\title{
CORE).(OES
}

CIÊNCIA E TECNOLOGIA

\section{A LOGÍSTICA REVERSA DE RESÍDUOS DE MEDICAMENTOS DOMICILIARES NO COMÉRCIO FARMACÊUTICO DO BAIRRO CENTRO, FORTALEZA, CEARÁ}

\author{
Juana Angélica Felipe Fernandes ${ }^{1}$, Érika Vieira de Paula Souza ${ }^{2}$, Lígia Nazaré Aguiar Silva ${ }^{3}$, \\ ROSSANA BARROS SILVEIRA ${ }^{4}$
}
${ }^{1}$ Universidad de La Serena, ${ }^{2}$ Universidade da Integração Internacional da Lusofonia Afro-Brasileira - UNILAB
${ }^{3}$ Pontificia Universidad Javeriana, ${ }^{4}$ Instituto Federal de Educação, Ciência e Tecnologia - IFCE <jaff294@hotmail.com>.<erikavpsouza@gmail.com>,<ligiaaguiarsilva@gmail.com>,<rossana@ifce.edu.br> 10.21439/conexoes.v15i0.1976

\begin{abstract}
Resumo. Entre o montante de resíduos sólidos urbanos produzidos diariamente incluem-se rejeitos com características de toxicidade, inflamabilidade, corrosividade e potencial contaminante, os quais merecem atenção especial, uma vez que são classificados pela NBR n ${ }^{\circ}$ 10.004/2004 como resíduos perigosos. Este é o caso dos resíduos de medicamentos domiciliares (RMD), como frascos, comprimidos, seringas etc., que podem ser gerados em residências e, quando descartados incorretamente, contaminam o solo e os corpos hídricos. Diante dessa problemática, a Lei cearense $\mathrm{n}^{\circ}$ 15.192, de 19 de julho de 2012, estabeleceu a implantação da logística reversa para RMD em farmácias, drogarias e distribuidores de medicamentos, para que o consumidor final tenha acesso a alternativas corretas de descarte. Nesse contexto, o presente trabalho buscou verificar, através de pesquisa de campo para registro fotográfico e preenchimento de formulário, o atendimento à esta Lei no Centro do Município de Fortaleza, bairro com maior número de estabelecimentos farmacêuticos do município. Os resultados mostram que apenas $7 \%$ das farmácias recebiam os RMD e que em mais de $60 \%$ dos estabelecimentos é perceptível o desconhecimento da normativa em questão, indicando uma possível falha na capacitação dos profissionais desses estabelecimentos, desconhecimento do proprietário/gestor do estabelecimento ou deficiência na fiscalização desse quesito por órgãos públicos. Portanto, é necessário que o poder público atue efetivamente com políticas públicas, fiscalização e outras ações, para que fabricantes e importadores de medicamentos - base do comércio de fármacos - apoiem a logística reversa de RMD iniciada no distribuidor final, ademais de medidas de educação ambiental para o consumidor final.
\end{abstract}

Palavras-chaves: Resíduos de Medicamentos domiciliares. Logística reversa. Farmácias. Fortaleza/CE.

\section{THE REVERSE LOGISTICS OF HOUSEHOLD WASTE MEDICINES IN PHARMACEUTICAL TRADE FROM DOWNTOWN OF FORTALEZA, CEARÁ.}

\begin{abstract}
Among the huge variety of waste disposed daily in the environment the ones that presents characteristics such as toxicity, inflammability, corrosivity and polluting potential, they deserve special attention, considering that they are classified by NBR $n^{\circ}$ 10.004/2004 as hazardous waste. A good example of hazardous waste is the Pharmaceutical one, such as flasks, pills, syringes etc., that can be produced in households and, when inappropriately disposed, may pollute the soil and water bodies. By facing this problem, the state Law $n^{\circ} 15.192$, from 19 of July of 2012, established the implantation of reverse logistic to household medicine waste, drugstores and carriers, in order to provide the final consumer with alternatives to appropriate dispose its pharmaceutical residues. In this context, the current article aims to verify, through field research for photographic record and form filling, the compliance with the Law in study, in the downtown of Fortaleza, which has the biggest number of drugstores of the municipality. The results show that only $7 \%$ of the drugstores received the RMD and that in more than $60 \%$ of the establishments it is perceptible the lack of knowledge of the norm in question, indicating a possible failure in the qualification of the professionals of these establishments, lack of knowledge of the owner/manager of the establishment or deficiency in the inspection of this question by public agencies, being viable that the public power acts effectively with public policies, inspection and other actions, so that manufacturers and importers of medicines - base of the commerce of drugs - support the reverse logistics of RMD initiated in the final distributor, besides measures of environmental education for the final consumer
\end{abstract}

Keywords: Household Pharmaceutical Waste. Reverse logistic. Drugstores. Fortaleza/CE. 


\section{INTRODUÇÃO}

Os resíduos sólidos, material intrínseco às atividades antrópicas, é geralmente item comum nas cidades, sendo uma fonte de impactos ambientais negativos quando disposto de forma inadequada. Entre o montante de resíduos lançados diariamente no meio ambiente incluem-se os rejeitos com características de toxicidade, inflamabilidade, corrosividade e potencial contaminante, os quais merecem atenção especial, uma vez que são classificados pela NBR n ${ }^{\circ} 10.004 / 2004$, como Classe I - perigosos.

A periculosidade destes produtos utilizados pelo homem pode, muitas vezes, ser ocultada frente sua alta disponibilidade e aquisição no mercado consumidor. Este é o caso dos fármacos, os quais, ao serem inutilizados, passam a resíduos de medicamentos e são descartados no ambiente de forma direta ou indireta, ou seja, através do descarte direto do medicamento em desuso, ou pelo metabolismo do consumidor final, respectivamente.

Caracterizados como fármacos fora de uso e seus derivados (caixas, bulas, frascos, comprimidos, seringas e etc.), os resíduos de medicamentos contaminam o solo e os corpos hídricos quando são descartados incorretamente por laboratórios, farmácias, indústrias farmacêuticas, estabelecimentos de saúde (hospitais, postos de saúde, clínicas, estabelecimentos veterinários, ambulatórios) ou residências, sendo, esta última, o interesse deste estudo.

Diante do exposto, através deste trabalho buscouse verificar, no Centro do município de Fortaleza/CE, bairro fortalezense com maior número de farmácias, o atendimento desses estabelecimentos à Lei $\mathrm{n}^{\circ} 15.192$, de 19 de julho de 2012, para analisar o novo sistema de gestão de resíduos de medicamentos domiciliares (RMD) com foco na logística reversa disponibilizada à população, a fim de subsidiar as tomadas de decisões para gestão dos RMD e, assim, reduzir os possíveis impactos ambientais.

\section{FUNDAMENTAÇÃO TEÓRICA}

A crescente população e suas demandas, junto à industrialização diversificada e acentuada, têm originado um volume crescente de resíduo em quantidade e diversidade. CEMPRE (2019) explica que a população global já ultrapassou o quantitativo de 7 bilhões de habitantes, e que geramos, em média, 3 bilhões de toneladas de lixo ao ano. Assim, quanto maior o incremento populacional, provavelmente, maior será a necessidade de produção de insumos direcionados ao consumo e maior a geração de resíduos sólidos.
Atualmente, o Estado do Ceará conta com 184 municípios em uma área de $148.920,472 \mathrm{~km}^{2}$, alcançando, em 2010, uma população de 8.452.381 habitantes (hab), dos quais $29 \%$ (2.452.185 hab) residem no município de Fortaleza (IPECE, 2017). Segundo o IBGE (2010), Fortaleza possui $314,930 \mathrm{~km}^{2}$ e densidade demográfica de Fortaleza de $7.786,44 \mathrm{hab} / \mathrm{km}^{2}$, enquanto o Estado possui apenas $56,76 \mathrm{hab} / \mathrm{km}^{2}$, estando clara uma maior pressão antrópica na capital cearense.

A abordagem da temática "resíduos" tem ampla difusão no Brasil, sendo definida, em nível Cearense, através da Política Estadual de Resíduos Sólidos do Estado do Ceará (PERS-CE), Lei n ${ }^{\circ} 16.032$, de 20 de junho de 2016, a qual caracteriza resíduos sólidos como:

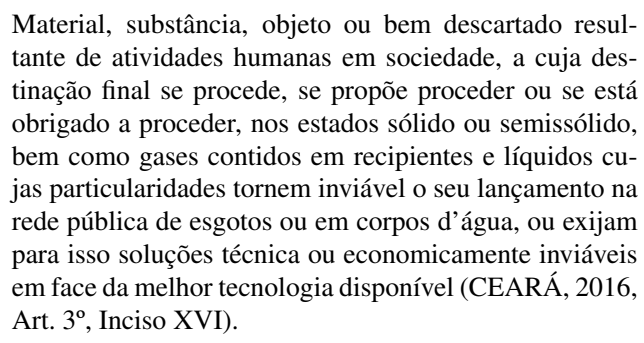
tante de atividades humanas em sociedade, a cuja destinação final se procede, se propõe proceder ou se está obrigado a proceder, nos estados sólido ou semissólido, bem como gases contidos em recipientes e líquidos cujas particularidades tornem inviável o seu lançamento na rede pública de esgotos ou em corpos d'água, ou exijam para isso soluções técnica ou economicamente inviáveis em face da melhor tecnologia disponível (CEARÁ 2016. Art. $3^{\circ}$, Inciso XVI)

De fato, toda atividade antrópica gera, em algum momento, um quantitativo de resíduos sólidos com características físicas e químicas diversas, os quais têm especificidades quanto à caracterização e às responsabilidades de gestão. Segundo CEMPRE (2019) e Fortaleza (1999), a responsabilidade pelos resíduos sólidos está vinculada à origem (domiciliar, comercial, público, serviços de saúde, Portos, Aeroportos, Terminais Rodoviários e Ferroviários, industrial, agrícola e resíduos da construção civil), sendo outras classificações adotadas por medidas de gestão, como, por exemplo, características físicas (seco ou molhado) ou composição química (orgânico ou inorgânico).

Para minimizar os impactos, a PNRS estabelece como alguns de seus objetivos o sexteto de etapas a serem consideradas na gestão de resíduos sólidos: não geração, redução, reutilização, reciclagem e tratamento dos resíduos sólidos, bem como disposição final ambientalmente adequada dos rejeitos; onde a logística reversa (LR) atua como ferramenta essencial. Segundo a PNRS, a LR é o instrumento de desenvolvimento formado por ações, procedimentos e meios para viabilizar a coleta e a restituição dos RS ao setor empresarial, para reaproveitamento, em seu ciclo ou em outros ciclos produtivos ou outra destinação final ambientalmente adequada, o que deve acontecer de forma independente do serviço público de limpeza urbana (BRASIL, 2010).

É importante destacar que a LR é imposta a fabricantes, importadores, distribuidores e comerciantes 
de pilhas e baterias, agrotóxicos, pneus, óleos lubrificantes, lâmpadas fluorescentes e eletroeletrônicos, de forma independente ao serviço público. Porém, considerando o grau e a extensão do impacto à saúde pública e ao meio ambiente dos resíduos gerados, pode relacionar-se a outros produtos embalados, na forma de disposição em regulamento, acordos setoriais ou termos de compromisso entre o poder público e o setor empresarial (BRASIL, 2012).

Nesse contexto, CEMPRE (2019) explica que aproximadamente $70 \%$ dos resíduos sólidos brasileiros são passíveis de reciclagem e reaproveitamento, ou seja, matéria-prima para diversos processos. No entanto, para que se obtenha qualquer insumo é necessário gestão, investimento e incentivo do governo, evitando gastos com tratamento de resíduos e aumentando a necessidade da retirada de matéria-prima da natureza para produção de bens de consumo. Infelizmente, os programas de coleta seletiva no Brasil englobam apenas $22 \%$ (1.227 de um total de 5.570) dos municípios, os quais atendem somente $17 \%$ (35 milhões) da população, ademais, estão, em sua maioria, localizados nas regiões Sul e Sudeste, evidenciando sua má distribuição espacial no território brasileiro (CEMPRE, 2019).

No Brasil, dos quase 70 milhões de toneladas de resíduos sólidos urbanos coletadas anualmente, $42 \%$ ainda têm como destino lixões e aterros controlados, considerados ambientalmente inadequados (SINDIVERDE, 2016). Com realidade semelhante a nacional, o Ceará tem $30 \%$ e $25 \%$ de seus resíduos domésticos encaminhados a aterros controlados e lixões, respectivamente, e apenas $45 \%$ têm como destino Aterros Sanitários, montantes oriundos da coleta de 0,858 $\mathrm{kg} /$ hab.dia, o que representa um total de 7.588 ton/dia (SINDIVERDE, 2016).

Os baixos índices de reciclagem disponibilizados pelos municípios à população e a disposição inadequada por deficiência quantitativa de aterros sanitários, bem como a falta de consciência da população, que perdura com ações inadequadas, como o descarte de resíduos em vias públicas e corpos hídricos, têm contribuído negativamente para a modificação do meio ambiente. Esse contexto se agrava frente à contínua transformação dos bens naturais em bens de consumo, o que pode modificar a natureza de produtos e originar componentes persistentes no meio ambiente, ou mesmo que dificultam o tratamento químico ou biológico de resíduos ou efluentes. Este é o caso dos resíduos de medicamentos, que em geral, têm sua gênese nos hospitais, clínicas humana ou veterinária, farmácias, drogarias, ambulatórios, postos de saúde e residências, sendo esta última, um ponto que merece destaque devido à alta possibilidade de descarte incorreto (instalações de esgotamento sanitário ou junto aos resíduos domésticos) por falta de orientação ou perspectivas de coleta seletiva.

Os RMD necessitam de manejo diferenciado, haja vista os riscos que apresentam à saúde humana e ao meio ambiente devido a sua periculosidade, advinda de produtos químicos e/ou patógenos, que após consumo, são eliminados através de processos metabólicos ou por meio de descarte (devido ao desuso ou data de validade expirada) e instalações hidro sanitárias ou juntamente a resíduos sólidos domésticos, fornecendo componentes que interagem com o ambiente e geram impactos negativos no solo e nos corpos de água. Neste tema, Borrely et al. (2012) explicam que a baixa volatilidade dos compostos farmacológicos indica que a sua distribuição ocorre através do transporte no ambiente aquático e na cadeia alimentar, o que foi detectado em corpos de água e, ademais, em estudos com animais, onde observou-se interferência na ação hormonal, com maior vulnerabilidade a cancros sensíveis às hormonas tais como tumores mamários, de próstata, ovarianos e uterinos. Outro problema são os efeitos dos antibióticos e estrogénios, que, respectivamente, têm o potencial de influenciar o desenvolvimento de bactérias resistentes e o sistema reprodutor dos organismos aquáticos, por exemplo induzindo a feminização dos peixes machos em rios contaminados Eman e Ball (2007), Kyrillos (2011).

Nessa mesma vertente, quando se trata especificamente de RMD, o controle e a prevenção de impactos ambientais pressupõem um manejo adequado desses rejeitos, o qual vincula-se à segregação adequada na fonte, ou seja, logo após sua geração. A coleta seletiva dos RMD evita o aumento do volume de resíduos perigosos e possibilita a reciclagem de parte do material recolhido, reduzindo custos e impactos ambientais.

\subsection{Problemática dos RMD}

O consumo de fármacos é uma realidade globalizada tanto para as empresas quanto para a população. De grande variedade no mercado, os medicamentos têm composição bastante multifacetada e, quando descartados inadequadamente, seus componentes interagem com o meio ambiente e geram impactos negativos no solo e nos corpos hídricos.

Os medicamentos podem ser encontrados tanto em estabelecimentos de saúde, quanto junto à população em seus estoques caseiros de medicamentos, que geralmente os mantêm para o caso de emergências. Atualmente, o Brasil possui o quarto maior mercado farmacêutico (US\$ 65,971 mil milhões), com um grande número de farmácias e lojas privadas de medicamentos (3,3: 10.000 farmácias/habitantes), hábitos de autome- 
dicação e nenhum programa nacional de retorno, a geração RMD está estimada em 56,6 g/per capita, ou 10,8 t/ano (PEREIRA; BARROS; PEREIRA, 2017). Perspectiva que avulta na capital cearense diante da centralização populacional, uma vez que em 2010, aproximadamente $29 \%$ da população estadual, 2.452.185 habitantes (hab), já residia em Fortaleza, cidade com maior densidade demográfica do estado, 7.786 hab por $\mathrm{km}^{2}$ (IBGE, 2010; IPECE, 2017). Pressupõe-se então, a concentração e aumento, subsequente e gradativo, do volume e impactos de RMD em Fortaleza.

Questiona-se, então, as opções de descarte adequado de RMD acessíveis à população, já que sua ausência pode culminar na eliminação de RMD em instalações hidrossanitárias e/ou no sistema de coleta de resíduos sólido domiciliar, o que Simas (2009) relaciona ao desconhecimento de impactos ambientais ou mesmo em opções corretas de coleta seletiva disponibilizados à população, destacando que o descarte se torna um agravante quando se trata de produtos específicos de quimioterápicos, antibióticos, hormônios, entre outros, cujo impacto no meio ambiente é maior.

Lima (2004) frisa que impactos ambientais surgem da forte interação entre dois fatores: o aumento populacional, que exige maior incremento na produção de alimentos e bens de consumo diretos; e o fator tecnológico de medicamentos, com a busca por novos medicamentos e o lançamento contínuo no mercado de novos produtos. Esse último fator é notável quando os dados do CRF-PR (2013) mostram que o setor farmacêutico cresceu continuamente nos últimos 10 anos. Sob esse ponto de vista, o cenário dos RMD agrava-se, já que novos resíduos e impactos derivam de uma série de componentes mais ou menos inéditos disponibilizados ao mercado consumidor.

Outro agravante detectado por Simas (2009) mostrou que em um sistema montado para coleta de RMD, $77 \%$ dos medicamentos devolvidos pelo consumidor tinham sua data de validade expirada, evidenciando que no sexteto dos resíduos (não geração, redução, reutilização, reciclagem, tratamento, disposição final) para medicamentos inservíveis, há uma provável deficiência na "não geração", ou seja, possivelmente há uma falta de orientação na aquisição e/ou estocagem dos medicamentos.

Esse cenário, toma maiores proporções quando somado a uma política pública e empresarial de baixa consistência na gestão de resíduos de fármacos disponibilizada ao consumidor final. É evidente a importância da gestão dos RMD, da conscientização dos usuários quanto ao descarte dos fármacos inservíveis e do papel dos fornecedores de medicamentos na implantação de mecanismos que não somente forneçam ao consumidor uma opção de descarte ambientalmente adequado, mas se utilize de todas as possíveis ferramentas de gestão ambiental no âmbito farmacêutico, uma vez que a segregação dos resíduos na fonte permite a identificação, classificação, caracterização e escolha de processos de disposição final para minimizar os impactos negativos vinculados ao RMD.

\subsection{Legislação para os RMD}

O Brasil possui a gestão de resíduos embasados na Política Nacional de Resíduos Sólidos (PNRS), Lei Federal no 12.305 , de 12 de agosto de 2010, regulamentada pelo Decreto $\mathrm{n}^{\circ}$ 7.404, de 23 de dezembro de 2010, a qual estabelece, de forma geral, que as organizações responsáveis por disponibilizar no mercado produtos que geram resíduos com impactos ambientais significativos devem manter procedimentos que os contenham ou reduzam, desde o momento de sua geração até sua destinação final, incluindo nesse cenário a logística reversa.

Na perspectiva acima, o quesito "resíduos de serviços de saúde" foi abordado em 1993, através do Conselho Nacional de Meio Ambiente (CONAMA), que estabeleceu sua primeira tratativa para os RSS através da Resolução $\mathrm{n}^{\circ}$ 05, afirmando a necessidade de tratar esses rejeitos. Em 2001, surge, então, a Resolução CONAMA n ${ }^{\circ} 283$, que não está mais em vigor, mas complementou, entre outros itens, a Resolução no 05/1993 do CONAMA, e abordou especificamente o tratamento e destinação final dos resíduos de saúde, de acordo com a tipologia.

Atualmente, para os resíduos de fontes variadas normalmente utiliza-se a classificação da NBR $\mathrm{n}^{\mathbf{o}}$ 10.004/2004, que emprega como critério o risco à saúde e ao meio ambiente, porém, a tipologia dos RSS é norteada principalmente pela Resolução da Diretoria Colegiada (RDC) $n^{\circ}$ 222/2018 da ANVISA e pela Resolução nº 358/2005 do CONAMA, conforme especificado abaixo:

- Grupo A - subdivididos de A1 a A5, aqueles que apresentam riscos de infecção devido à presença de agentes biológicos;

- Grupo B - categoria com substâncias químicas que podem apresentar risco à saúde pública e ao meio ambiente devido às suas características de inflamabilidade, corrosividade, reatividade e/ou toxicidade;

- Grupo C - resíduos com radionuclídeos em quantidades superiores aos limites de eliminação especi- 
ficados em normas do Conselho Nacional de Energia Nuclear (CNEN) para os quais a reutilização é imprópria ou não prevista;

- Grupo D - rejeitos que não apresentam risco biológico, químico e/ou radiológico à saúde e ao meio ambiente. São similares aos resíduos domiciliares;

- Grupo E - engloba o material perfurocortantes ou escarificantes contaminados, tais como lâminas, espátulas, agulhas, escalpes, ampolas de vidro, limas endodônticas e demais similares.

Dessa forma, o presente estudo tem seu foco nos resíduos do Grupo B, categoria que abrange os medicamentos vencidos, contaminados, interditados ou não utilizados, sendo sua classificação, quantificação e segregação, uma etapa fundamental para análise e implementação de ferramentas de gestão dos RMD, como por exemplo o Plano de Gerenciamento de Resíduos de Serviço de Saúde (PGRSS), item obrigatório para os estabelecimentos de serviço de saúde, de acordo com $\mathrm{AN}-$ VISA (2006) e CONAMA (2005).

Recentemente, o Decreto Federal $n^{\circ} 10.388$ de 5 de junho de 2020, regulamentou o $\S 1^{\circ}$ da Lei $n^{\circ}$ 12.305/2010, instituindo a Logística Reversa de medicamentos domiciliares vencidos ou em desuso, de uso humano, industrializados e manipulados, e de suas embalagens após o descarte pelos consumidores. O Decreto, em seu Capítulo VI, informa que, na segunda fase de implementação, serão estabelecidas farmácias e drogarias como pontos fixos para recebimento dos medicamentos domiciliares vencidos ou em desuso descartados pelos consumidores, determinando que o custo da disponibilização de local de contentores, transporte e destinação final ficarão às expensas dos estabelecimentos.

O descarte correto de resíduos sólidos abordado no PGRSS e na logística reversa possui seu embasamento no acervo legal brasileiro, porém, muitas vezes não é estabelecido, implementado ou mantido por setores responsáveis, podendo, inclusive, ser totalmente desconhecido. Vale ressaltar que a tipologia dos RMD com prazo de validade expirado ou não, provenientes de domicílios, claramente abordada na legislação cearense, a qual estabeleceu no Artigo 33o da Política Estadual de Resíduos Sólidos (PERS), a responsabilidade de comerciantes e distribuidores pela recepção destes produtos e subsequente devolução ao fabricante ou importador, devendo, estes últimos, encarregar-se pelo tratamento e disposição final ambientalmente adequados (CEARÁ 2016).

Ainda na perspectiva supracitada, o cenário cearense dos distribuidores de medicamentos no quesito
RMD antecede a PERS, com destaque na Lei no 15.192, de 19 de julho de 2012, a qual responsabiliza farmácias, drogarias e distribuidores de medicamentos a dispor em seus estabelecimentos espaços, adequados ao uso pela população, para receberem os medicamentos inservíveis, devendo atender às seguintes condições:

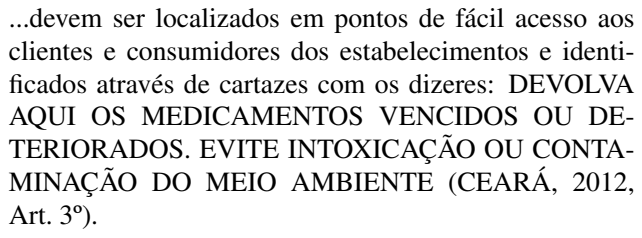

Nesse contexto, a coleta de RMD nos pontos comerciais de fármacos pode ser uma ferramenta de gestão importante para minimizar riscos ambientais inerentes à sua disposição inadequada, vista que aproveita a segregação na origem, e dessa forma pode reduzir custos e impactos advindos do transporte, tratamento e disposição final.

\section{METODOLOGIA}

Este estudo tem finalidade exploratória e descritiva, sendo orientado a expor o estado situacional da implementação da logística reversa de RMD em estabelecimentos farmacêuticos fortalezenses, enfocando-se na análise da disponibilização à população de um local específico para recebimento de fármacos inservíveis, conforme Lei estadual $n^{\circ} 15.192 / 2012$. A pesquisa exploratória tem por objetivo aproximar-se do tema, criando maior familiaridade do pesquisador com o ambiente, fato ou fenômeno, prospectando materiais que possam informar a real importância do problema, o que já existe a respeito ou até novas fontes de informação, o que normalmente é feito através de levantamento bibliográfico e documental, entrevistas com profissionais da área, observações in loco dentre outros (LAKATOS; MARCONI, 2003).

A pesquisa estrutura-se em informações secundárias da área das ciências farmacêuticas e ambientais, utilizando-se de revisão bibliográfica e documental para o entendimento e construção do conhecimento científico. Para tal, coletou-se informações de jornais, artigos científicos, legislações, bases de dados tais como Scielo, ScienceDirect, Web of Science e Scopus, sites dos órgãos públicos, ademais da análise de documentos do Conselho Regional de Farmácia do Ceará (CRF) relacionados a estabelecimentos farmacêuticos cearenses, população de interesse deste estudo. A busca de dados secundários considerou pesquisas em português, espanhol e inglês, utilizando-se, para tal, os seguintes descritores: "resíduos de medicamentos domiciliares", 
"medicamentos inservíveis", "fármacos domiciliarios", "residuos de medicamentos domiciliarios", "household pharmaceuticals"e "household waste medicine".

Para coleta de dados, utilizaram-se como ferramentas o questionário estruturado e a técnica de observação, abordando: dados da farmácia (nome e endereço); oferta de coletor para RMD em área acessível ao consumidor; disposição de cartaz informativo sobre a LR de RMD; fornecimento de informação ao usuário sobre recebimento de resíduos de medicamentos; e conhecimento sobre a Lei estadual $n^{\circ} 15.192 / 2012$. A coleta de dados manteve prioridade na aquisição de informações junto ao responsável farmacêutico ou proprietário dos estabelecimentos em estudo. As informações obtidas foram registradas no software Excel e posteriormente analisadas através de um enfoque qualitativo, uma vez que (BOGDAN; BIKLEN, 1994) apresentam como principais características da pesquisa qualitativa a essência descritiva, tendo o ambiente natural como fonte dos dados e o pesquisador como instrumentochave, preocupados com o processo e não somente com os resultados e produto, tendendo a analisar seus dados indutivamente.

Destaca-se que a amostragem dos estabelecimentos farmacêuticos foi definida de forma não estatística, com delimitação orientanda em base à informação qualiquantitativa solicitada ao Conselho Regional de Farmácia do Ceará (CRF), na qual identificou-se que a Capital Cearense se destaca como o município com maior número de estabelecimentos farmacêuticos, $32,6 \%$ do total, e 677 pontos de comercialização. Resultado muito aquém de outros municípios, como Juazeiro do Norte, Maracanaú, Caucaia e Sobral, que possuem uma média de 2,6\% de estabelecimentos em pauta (CRF-CE 2016). Ressalta-se que em todos os municípios aproximadamente $60 \%$ dos estabelecimentos são do tipo "farmácia comercial e drogaria" em comparação aos demais: Central de Abastecimento Farmacêutico (CAF), distribuidora, farmácias de manipulação, hospitalares, públicas, homeopáticas, unidade de saúde/popular.

Nessa perspectiva, definiu-se o município de Fortaleza como área para verificação do atendimento, nas farmácias comerciais, à Lei cearense $\mathrm{n}^{\circ} 15.192$, de 19 de julho de 2012. Porém, para reduzir a área de amostragem, custos e tempo de verificação em campo, buscouse o bairro que também apresentasse o maior número de estabelecimentos farmacêuticos, e, nesse caso, houve um destaque percentual de $10,7 \%$ para o Centro de Fortaleza, o qual possui 72 pontos de comércio disponíveis ao consumidor final (Tabela 1 .

Posteriormente, realizou-se a pesquisa de campo durante o mês de julho de 2018, com o objetivo de veri- ficar a disponibilização, em farmácias, de um local específico para a coleta de RMD oriundos do consumidor final.

A intenção deste trabalho foi analisar o uso, no mercado farmacêutico, da ferramenta de logística reversa para RMD, discutindo não só a função da farmácia comercial para mitigar possíveis impactos ambientais resultantes da comercialização de seus produtos, mas a contribuição da legislação e da fiscalização na gestão de resíduos de medicamentos gerados pela população, uma vez que a deficiência de alternativas para descarte de fármacos pelo consumidor final poderá ocasionar prejuízos para a sociedade e para o meio ambiente.

\section{RESULTADOS E DISCUSSÕES}

\subsection{A logística reversa de RMD no comércio farma- cêutico do Centro de Fortaleza}

O Centro de Fortaleza abrange uma área de $5,45 \mathrm{~km}^{2}$ e população de 24.775 habitantes, delimitado ao norte, pelas avenidas Historiador Raimundo Girão, Almirante Barroso e Pessoa Anta, ruas Adolfo Caminha e Santa Terezinha, e Avenida Presidente Castelo Branco (Leste - Oeste); ao leste, pela rua João Cordeiro; ao oeste, pelas avenidas Filomeno Gomes e Padre Ibiapina; e ao sul, pela Avenida Domingos Olímpio e início da Avenida Antônio Sales, sendo esta uma área gerida pela Regional do Centro, conforme Figura 1(FORTALEZA, 2014).

Figura 1: Delimitação da área do Centro de Fortaleza/CE.

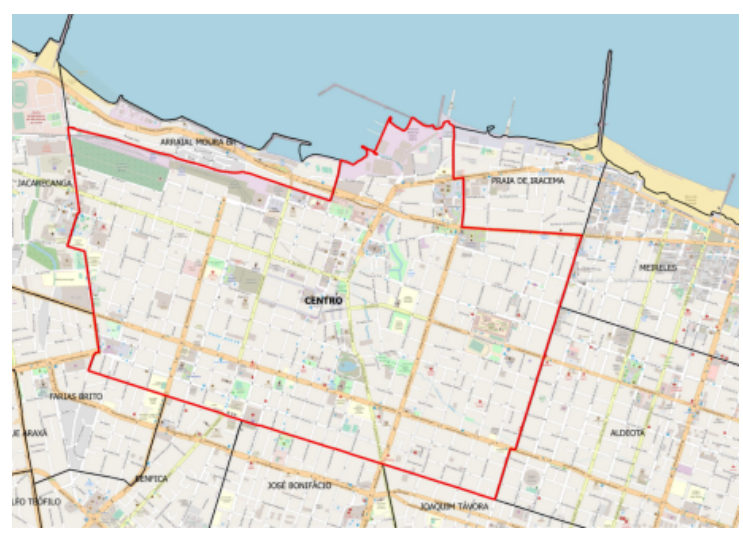

Fonte: Google Earth; Fernandes (2018).

De acordo com CEARÁ (2012), as farmácias e drogarias comerciais cearenses devem fornecer a coleta de RMD ao consumidor final, disponibilizando espaços, de fácil acesso aos clientes e consumidores dos estabelecimentos, identificados através de cartazes com os dizeres: "DEVOLVA AQUI OS MEDICAMENTOS 

CENTRO, FORTALEZA, CEARÁ

Tabela 1: Estabelecimentos Farmacêuticos Fortalezenses, registrados por Bairro, no CRF-CE.

\begin{tabular}{|c|c|c|c|c|c|c|c|c|}
\hline $\mathbf{N}^{\mathbf{o}}$ & Bairro & CAF & Distribuidora & Drogaria & $\begin{array}{l}\text { Farmácia } \\
\text { Comercial }\end{array}$ & Outros* & Total & $\%$ \\
\hline 1 & Aldeota & & 13 & 7 & 33 & 45 & 98 & 9,0 \\
\hline 2 & $\begin{array}{c}\text { Conjunto } \\
\text { Ceará }\end{array}$ & & & & 16 & 5 & 21 & 1,9 \\
\hline 3 & Centro & & 12 & 2 & 70 & 33 & 117 & 10,7 \\
\hline 4 & Fátima & & 5 & 1 & 11 & 17 & 34 & 3,1 \\
\hline 5 & Meireles & & 4 & 3 & 21 & 9 & 37 & 3,4 \\
\hline 6 & Messejana & 1 & 6 & 2 & 27 & 20 & 56 & 5,1 \\
\hline 7 & Parangaba & & 3 & 1 & 19 & 10 & 33 & 3,0 \\
\hline \multirow[t]{2}{*}{8} & $\begin{array}{c}\text { Bairros } \\
\text { Restantes }\end{array}$ & ** & & & & & 693 & 63,6 \\
\hline & Total & 1 & 43 & 16 & 197 & 139 & 1089 & 100 \\
\hline
\end{tabular}

Fonte: Adaptado de CRF-CE (2016).

* Demais estabelecimentos farmacêuticos, excetuando-se CAF, Distribuidora, Drogaria e Farmácia Comercial.

** Todos os estabelecimentos da área de farmácia: farmácias de manipulação, hospitalares, públicas, homeopáticas, unidade de saúde/popular, CAF, Distribuidora, Farmácias comercial e drogaria.

VENCIDOS OU DETERIORADOS. EVITE INTOXICAÇÂO”. Tais quesitos foram averiguados durante a pesquisa de campo em 41 farmácias ou drogarias localizadas no Centro do Município de Fortaleza/CE, sendo os resultados apresentados a seguir (Tabela 2 e Figura 2):

Figura 2: Localização das farmácias e drogarias do Centro de Fortaleza, utilizando marcadores indicativos das áreas para descarte de RMD, conforme padrão de cores utilizado na Tabela 2

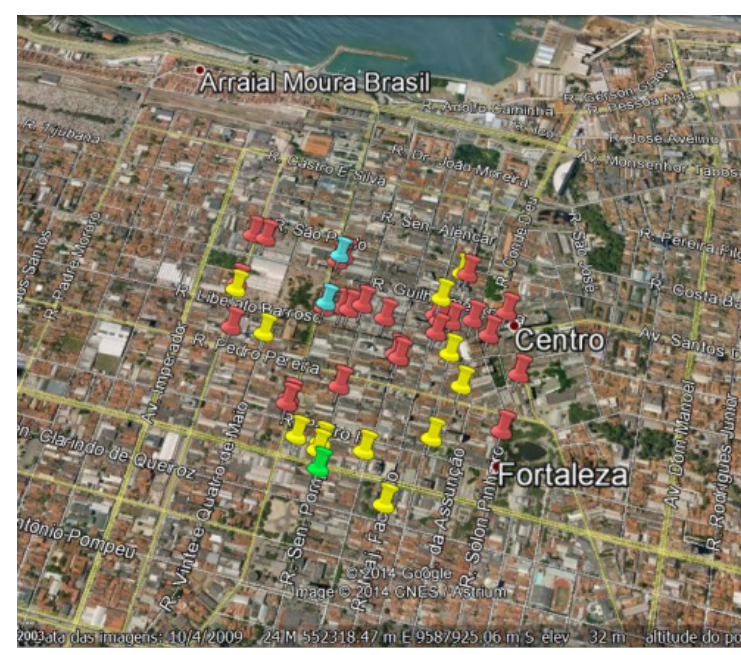

Fonte: Google Earth, 2018; Fernandes, 2018.

Os resultados mostram que apenas 1 estabelecimento atende a todos os quesitos determinados por Ceará (2014), ou seja, dispõe de um espaço com coletor para RMD em local de fácil acesso ao cliente, e car- taz informativo e educativo sobre a temática (Figura 3), enquanto 2 destes recebem os RMD, porém não dispõem de coletor acessível, contando apenas com cartaz, devendo, para este caso, o consumidor final ter conhecimento sobre o assunto e questionar os funcionários para que ocorra a entregam dos medicamentos inservíveis (Figura 2).

Nos demais 38 estabelecimentos visitados, não foram observados coletor ou informação ao consumidor final, valendo ressaltar que apenas $11(27 \%)$ tinham algum conhecimento sobre o assunto e chegavam a indicar outros estabelecimentos para coleta; 1 (2\%) tinha conhecimento e lembrou do impasse em atender à legislação, já que esta não define os responsáveis para arcar com os custos de tratamento dos RMD que seriam recebidos pela população; e as demais 26 (63\%) lojas desconheciam o sistema de logística reversa estabelecido por lei.

Entre os que desconheciam a obrigatoriedade na coleta de resíduos de medicamentos pelo comércio farmacêutico, 2 (5\%) orientaram que fosse buscado o descarte junto ao Órgão de Saúde do Município ou a ANVISA; 2 (5\%) disseram que não trabalham com esse tipo de programa social; 2 (5\%) orientaram descartar na coleta de resíduos domiciliares realizada pela prefeitura; $2(5 \%)$ afirmaram que a prefeitura disponibilizava, na praça do Centro de Fortaleza, um "incinerador" para os resíduos da farmácia, no qual o "lixo" era queimado e que a população poderia destinar seus próprios RMD no mesmo local; enquanto os outros se abstiveram do tema, não tecendo comentários sobre a questão.

A falta de conhecimento e atendimento à Lei cea- 
Tabela 2: Presença de área para descarte de RMD nas farmácias do Centro de Fortaleza/CE.

\begin{tabular}{ccccc}
\hline $\begin{array}{c}\text { Tipo de } \\
\text { estabelecimento }\end{array}$ & $\begin{array}{c}\text { Possui } \\
\text { e está } \\
\text { adequada }\end{array}$ & $\begin{array}{c}\text { Possui, mas não está } \\
\text { adequada (falta coletor } \\
\text { ou cartaz em área de } \\
\text { acesso livre) }\end{array}$ & $\begin{array}{c}\text { Não possui, mas tem } \\
\text { conhecimento e indica } \\
\text { outra farmácia/fabricante } \\
\text { para coleta }\end{array}$ & $\begin{array}{c}\text { Não possui e não tem } \\
\text { conhecimento sobre } \\
\text { o assunto }\end{array}$ \\
\hline $\begin{array}{c}\text { Farmácias ou } \\
\text { Drograrias }\end{array}$ & 1 & 2 & 12 & 26 \\
$\%$ & $2 \%$ & $5 \%$ & $29 \%$ & $64 \%$ \\
\hline
\end{tabular}

Fonte: Fernandes (2018).

Figura 3: Descarte de RMD em coletor acessível ao consumidor final, disponível em farmácia localizada no Centro de Fortaleza.

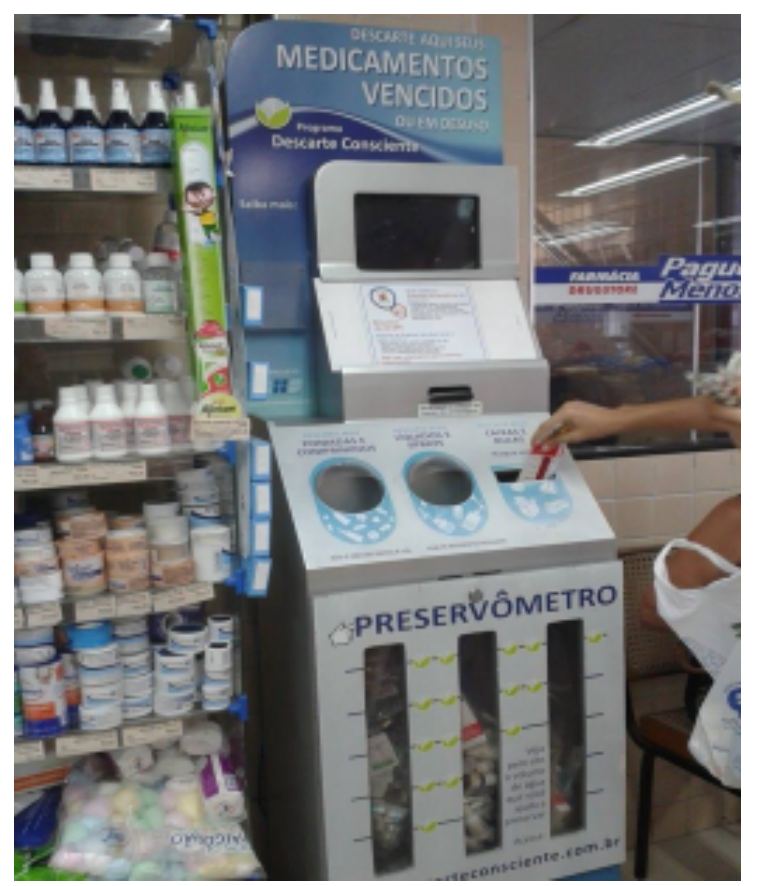

Fonte: Fernandes (2018).

rense sobre a LR de RMD pode ter relação com os isolados esforços normativos individuais de estados e municípios, que tentam superar o vazio normativo nacional em relação aos RMD, o que dificulta a estruturação de um plano de ação de maior envergadura, ou seja, que inclua todos os stakeholders envolvidos no comércio de medicamentos, para efetivar a coleta e tratamento dos RMD. Essa realidade também é vivenciada por outros países latino-americanos, como a Argentina, que mantém ações de LR de RMD isoladas, no âmbito de municípios (OLMOS, 2016); e o Uruguai, onde não há normativas aplicáveis (CONSIGLIO, 2018); o que destaca a importância do comprometimento e o esforço nacional na temática em discussão.
Figura 4: Cartaz sobre descarte de RMD localizado em Farmácia do Centro de Fortaleza.

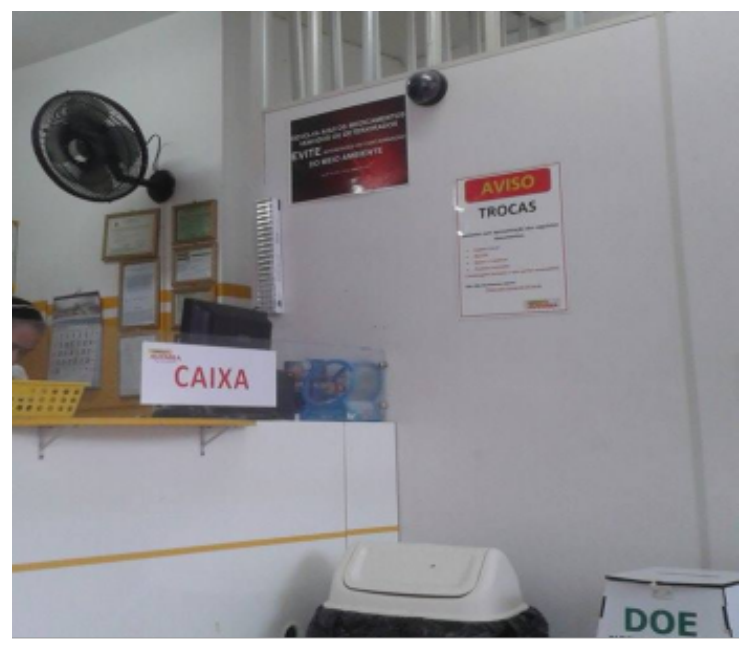

Fonte: Fernandes (2018).

Apesar da importância normativa, outros fatores, como quesitos informativos e de conscientização de consumidores, devem ser considerados na LR de RMD. Como exemplo, (BETTINGTON et al., 2018) mostram que após a implementação do Projeto Nacional de Retorno e Eliminação de Medicamentos Indesejados (RUM, em inglês), dos 4.302 entrevistados que relataram ter RMD, 67\% descartava estes rejeitos junto aos resíduos domiciliares e cerca de $25 \%$ nas instalações hidrossanitárias. Apenas 17,6\% dos entrevistados sabiam do Projeto RUM, embora, uma vez informados, 91,7\% tenham dito que o utilizariam.

Nesse contexto, é fundamental que as normativas supracitadas incorporem estratégias de educação ambiental e informação sobre LR de RMD ao consumidor de medicamentos, onde os profissionais de saúde poderiam cumprir papel fundamental para auxiliar os consumidores a gerir os seus medicamentos, com métodos ou ferramentas que identifiquem rotineiramente os RMD e informem aos consumidores sobre os métodos apropri- 
A LOGÍSTICA REVERSA DE RESÍDUOS DE MEDICAMENTOS DOMICILIARES NO COMÉRCIO FARMACÊUTICO DO BAIRRO CENTRO, FORTALEZA, CEARÁ

ados de eliminação.

\section{CONCLUSÃO}

A lei cearense $\mathrm{n}^{\mathrm{o}}$ 15.192, de 19 de julho de 2012, destaca a importância de manter uma alternativa de descarte correto para o consumidor final de medicamentos, pois caso não a encontre, este não terá escolhas a não ser a disposição na coleta municipal de resíduos sólidos ou no sistema de esgotamento sanitário, impactando, dessa forma, o solo e os corpos hídricos. No entanto, esta lei ainda é desconhecida por considerável quantidade de estabelecimentos farmacêuticos, mais de $60 \%$ das farmácias e drogarias visitadas na pesquisa, indicando uma possível falha na capacitação dos profissionais desses estabelecimentos, desconhecimento do proprietário/gestor do estabelecimento, ou deficiência na fiscalização desse quesito por órgãos públicos. Nesse sentido, é preciso maior empenho na fiscalização do atendimento à lei cearense $\mathrm{n}^{\circ} 15.192$, de 19 de julho de 2012, pelo órgão ambiental ou ANVISA, para que seja alavancada a gestão farmacêutica nesse quesito.

Por outro lado, o estado e o município lançam leis de controle de impactos gerados por resíduos sólidos perigosos, como o RMD, mas apenas posteriormente é que gesticulam com as empresas ou fabricantes sobre estas políticas públicas, gerando entraves, principalmente financeiros, no cumprimento legal pelos estabelecimentos em estudo. É preciso que o poder público atue efetivamente com políticas públicas, ou ações afins, para que fabricantes e importadores de medicamentos, a base do comércio de fármacos, apoiem a logística reversa iniciada no distribuidor final (farmácias e drogarias).

Diante das reduzidas alternativas de descarte apropriado de RMD nos estabelecimentos farmacêuticos, além de ser consciente ambientalmente, o consumidor tem de perseverar para destinar os fármacos inservíveis adequadamente. Nesse âmbito, a educação ambiental, por meio de campanhas de conscientização etc., ganha relevância para impulsar comportamentos inerentes a um cidadão consciente, responsável e participativo na coleta de RMD.

As mudanças nos sistemas de gestão de RMD devem ser adotadas, mesmo que paulatinamente, empregando-se postura de evolução e não revolução, para que sejam superados os entraves econômicos e culturais das empresas e da população.

\section{REFERÊNCIAS}

ABNT. NBR no 10.004: 2004. Classifica os resíduos sólidos quanto aos seus potenciais ao meio ambiente e à saúde pública. Rio de Janeiro: ASSOCIAÇÃO

BRASILEIRA DE NORMAS TÉCNICAS, 2004.

ANVISA. Gerenciamento dos resíduos do serviço de saúde. Tecnologia em Serviço de Sáude. Ministério da Saúde. Brasília: Agencia Nacional de Vigilância Sanitária, 2006. Disponível em: $<$ http://bvsms.saude.gov.br/bvs/publicacoes/manual_ gerenciamento_residuos.pdf> Acesso em: 1 abr. 2018.

BETTINGTON, E.; SPINKS, J.; KELLY, F.; GALLARDO-GODOY, A.; NGHIEM, S.; WHEELER, A. J. When is a medicine unwanted, how is it disposed, and how might safe disposal be promoted? insights from the australian population. Australian Health Review, CSIRO Publishing, v. 42, n. 6, p. 709-717, 2018.

BOGDAN, R.; BIKLEN, S. Características da investigação qualitativa. In: Investigação qualitativa em educação: uma introdução à teoria e aos métodos. Porto: Porto Editora, 1994. p. 47-51.

BORRELY, S. I.; CAMINADA, S. M. L.; PONEZI, A. N.; SANTOS, D. R. d.; SILVA, V. H. O. Contaminação das águas por resíduos de medicamentos: ênfase ao cloridrato de fluoxetina. Mundo da Saúde, v. 36, n. 4, p. 556-563, 2012.

BRASIL. Decreto $\mathbf{n}^{\circ} \mathbf{7 . 4 0 4}$, de 23 de dezembro de 2010. Regulamenta a Lei no 12.305, de 2 de agosto de 2010, que institui a Política Nacional de Resíduos Sólidos, cria o Comitê Interministerial da Política Nacional de Resíduos Sólidos e o Comitê Orientador para a Implantação dos Sistemas de Logística Reversa, e dá outras providências. 2010. Disponível em: <http://www.planalto.gov.br/ccivil_03/ _Ato2007-2010/2010/Decreto/D7404.htm> Acesso em: 8 nov. 2018.

RDC no 222, de 28 de março de 2018. Boas Práticas de Gerenciamento de Resíduos de Saúde. Ministério da Saúde. Agência Nacional de Vigilância Sanitária (ANVISA). Diário Oficial da União nº61. 2018. Disponível em: <http://portal.anvisa.gov.br/ documents/10181/3427425/RDC_222_2018_.pdf/ c5d3081d-b331-4626-8448-c9aa426ec410>. Acesso em: 4 set. 2018 .

Decreto $\mathrm{n}^{\circ} \mathbf{1 0 . 3 8 8}$, de 5 de junho de 2020. Regulamenta o $\S 1^{\circ}$ do caput do art. 33 da Lei $n^{\circ} 12.305$, de 2 de agosto de 2010 , e institui o sistema de logística reversa de medicamentos domiciliares vencidos ou em desuso, de uso humano, industrializados e 
A LOGÍSTICA REVERSA DE RESÍDUOS DE MEDICAMENTOS DOMICILIARES NO COMÉRCIO FARMACÊUTICO DO BAIRRO CENTRO, FORTALEZA, CEARÁ

manipulados, e de suas embalagens após o descarte pelos consumidores. 2020. Disponível em: <http://www.planalto.gov.br/ccivil_03/ _Ato2019-2022/2020/Decreto/D10388.htm> Acesso em: 10 jul. 2020.

CEARÁ. Governo do Estado. Assembléia legislativa. Lei $n^{0}$ 15.192, de 19 de julho de 2012 (D.O. 24.07.12). Define normas para o descarte de medicamentos vencidos e/ou fora de uso. 2012. Disponível em: <http://www.al.ce.gov.br/legislativo/legislacao5/ leis2012/15192.htm>. Acesso em: 8 nov. 2018.

Lei $\mathrm{n}^{0} \mathbf{1 6 . 0 3 2}$ de 20 de junho de 2016. Institui a Política Estadual de Resíduos Sólidos no âmbito do estado do Ceará. 2016. Disponível em: <https://www.cidades.ce.gov.br/wp-content/uploads/ sites/12/2018/03/16032Residuos.pdf> Acesso em: 10 dez. 2018.

CEMPRE. CEMPRE REVIEW 2019. 2019.

Disponível em: <http://cempre.org.br/upload/ CEMPRE-Review2019.pdf $>$. Acesso em: $12 \mathrm{dez}$. 2019.

CONAMA. Ministério do Meio Ambiente. Resolução no 358, de 29 de abril de 2005. Diário Oficial da União 84: de 4 de maio de 2005, Seção 1, páginas 63-65. 2005. Disponível em: <http://wWw.mma.gov.br/port/conama/legislacao/ CONAMA_RES_CONS_2005_358.pdf > Acesso em: 4 set. 2018.

CONSIGLIO, L. D. Programa de recolección de residuos de medicamentos vencidos y/o en desuso domiciliarios para la ciudad de Concepción del Uruguay. Tese (Especialização em Engenharia Ambiental) - Facultad Regional Concepción del Uruguay, Concepción, 2018.

CRF-CE. Relatório quantitativo de estabelecimentos registrados por bairro. Conselho Regional de Farmácia do Estado do Ceará - CRF, 2016. crfce@crfce.org.br. 2016.

CRF-PR. Setor Farmacêutico cresce há 10 anos no Brasil, 2013. 2013. Disponível em: <http://www. crf-pr.org.br/site/noticia/visualizar/id/4320/?Setor_ Farmaceutico_cresce_ha_10_anos_no_Brasil.html> Acesso em: 24 set. 2018.

EMAN, A. A.; BALL, D. E. Disposal of unwanted medicines from households in kuwait. Pharmacy world \& science, Springer, v. 29, n. 4, p. 368-373, 2007.
FERNANDES, J. A. F. Documentação fotográfica da pesquisa. Fortaleza: IFCE, 2018.

FORTALEZA. 1999. Lei $\mathbf{n}^{\circ} 8.408$, de 24 de dezembro de 1999. Estabelece normas de responsabilidade sobre a manipulação de resíduos produzidos em grande quantidade. 1999. Disponível em: <http://www.fortaleza.ce.gov.br/emlurb/ lei-no-8408-de-24-de-dezembro-de-1999> Acesso em: 25 mar. 2018

Regionais. 2018. Disponível em: $\overline{<\mathrm{http}}$ ://www.fortaleza.ce.gov.br/regionais> Acesso em: 25 mar. 2018.

GONZÁLEZ, A. D.; PETRIS, A. J. Revisão sobre resíduos de serviço de saúde: proposta de um plano de gerenciamento para farmácia. Revista Espaço para a Saúde, Londrina, v. 8, n. 2, p. 01-10, 2007.

IBGE. Censo demográfico. 2010. Disponível em: $<$ http://www.ibge.gov.br/estadosat/perfil.php?sigla= ce> Acesso em: 25 mar. 2018.

IPECE. Anuário estatístico do Ceará. 2017.

Disponível em: <http://www2.ipece.ce.gov.br/ publicacoes/anuario/anuario2017/demografia/ populacao.htm>, Acesso em: 25 mar. 2018.

KYRILLOS, G. Medications collected for disposal by outreach pharmacists in australia. Pharmacy world \& science, Springer, v. 32, n. 1, p. 52-58, 2011.

LAKATOS, E. M.; MARCONI, M. d. A.

Fundamentos de metodologia científica. 5. ed. São Paulo: Atlas, 2003.

LIMA, L. M. Q. LIXO: Tratamento e Biorremediação. 3. ed. São Paulo: Hemus, 2004.

OLMOS, D. ¿ qué pasa con los medicamentos vencidos de generación domiciliaria en la ciudad de córdoba? Bitácora Digital, v. 3, n. 7, p. 1-3, 2016.

PEREIRA, A. L.; BARROS, R. T. de V.; PEREIRA, S. R. Pharmacopollution and household waste medicine (hwm): how reverse logistics is environmentally important to brazil. Environmental Science and Pollution Research, Springer, v. 24, n. 31, p. 24061-24075, 2017.

SIMAS, B. d. R. Caracterização dos medicamentos descartados por usuários da farmácia popular do Brasil. Porto Alegre, 2009.

SINDIVERDE. Recicla Ceará 2016: Anuário do setor de reciclagem do Ceará. Fortaleza, 2016. 